\title{
Azadioxatriangulenium and diazaoxatriangulenium
}

\section{quantum yields and fundamental photophysical properties}

Bogh, Sidsel Ammitzbøll; Simmermacher, Mats; Westberg, Michael; Bregnhøj, Mikkel; Rosenberg, Martin; De Vico, Luca; Veiga, Manoel; Laursen, Bo Wegge; R. Ogilby, Peter; Sauer, Stephan P. A.; Sørensen, Thomas Just

\section{Published in:}

ACS Omega

DOI:

10.1021/acsomega.6b00211

Publication date:

2017

Document version

Publisher's PDF, also known as Version of record

Document license:

Other

Citation for published version (APA):

Bogh, S. A., Simmermacher, M., Westberg, M., Bregnhøj, M., Rosenberg, M., De Vico, L., Veiga, M., Laursen, B. W., R. Ogilby, P., Sauer, S. P. A., \& Sørensen, T. J. (2017). Azadioxatriangulenium and diazaoxatriangulenium: quantum yields and fundamental photophysical properties. ACS Omega, 2(1), 193-203. https://doi.org/10.1021/acsomega.6b00211 


\title{
Azadioxatriangulenium and Diazaoxatriangulenium: Quantum Yields and Fundamental Photophysical Properties
}

\author{
Sidsel A. Bogh, ${ }^{\dagger}$ Mats Simmermacher, ${ }^{\dagger}$ Michael Westberg, ${ }^{\ddagger}$ Mikkel Bregnhøj, ${ }^{\ddagger}$ Martin Rosenberg, ${ }^{\dagger}$ \\ Luca De Vico, ${ }^{\dagger}$ Manoel Veiga, ${ }^{\S}$ Bo W. Laursen, ${ }^{\dagger}$ Peter R. Ogilby, ${ }^{\ddagger}$ Stephan P. A. Sauer, ${ }^{\dagger}$ \\ and Thomas Just Sørensen*,ंi
}

${ }^{\dagger}$ Nano-Science Center \& Department of Chemistry, University of Copenhagen, Universitetsparken 5, 2100 København $\varnothing$, Denmark ${ }^{\ddagger}$ Department of Chemistry, Aarhus University, Langelandsgade 140, 8000 Aarhus C, Denmark

${ }^{\S}$ PicoQuant GmbH, Rudower Chaussee 29, 12489 Berlin, Germany

\section{Supporting Information}

\begin{abstract}
Over the last decade, we have investigated and exploited the photophysical properties of triangulenium dyes. Azadioxatriangulenium (ADOTA) and diazaoxatriangulenium (DAOTA), in particular, have features that make them useful in various fluorescence-based technologies (e.g., bioimaging). Through our work with ADOTA and DAOTA, we became aware that the reported fluorescence quantum yields $\left(\phi_{\mathrm{fl}}\right)$ for these dyes are lower than their actual values. We thus set out to further investigate the fundamental structure-property relationships in these unique conjugated cationic systems. The nonradiative processes in the systems were explored using transient absorption spectroscopy and time-resolved emission spectroscopy in combination with computational chemistry. The influence of molecular oxygen on the fluorescence properties was explored, and the singlet oxygen sensitization efficiencies of ADOTA and DAOTA were determined. We conclude that, for these dyes, the amount of nonradiative deactivation of the first excited singlet state $\left(S_{1}\right)$ of the azaoxa-triangulenium fluorophores is low, that the rate of such deactivation is slower than what is observed in common cationic dyes, that there are no observable radiative transitions occurring from the first excited triplet state $\left(\mathrm{T}_{1}\right)$ of these dyes, and that the efficiency of sensitized singlet oxygen production is low $\left(\phi_{\Delta} \leq 10 \%\right)$. These photophysical results provide a solid base upon which technological applications of these fluorescent dyes can be built.
\end{abstract}

\section{INTRODUCTION}

The triangulenium dyes constitute a group of organic dyes that have a planar, fully conjugated triangulenium core in common. $^{1-4}$ The structure is formally a cationic heterotriangulene, ${ }^{5}$ a structure first discussed by Clar. ${ }^{6}$ The first triangulenium dye was prepared by Martin and Smith in 1964, ${ }^{7}$ and the compound class has since been expanded with dyes that can be considered as extended rhodamines, ${ }^{1,8,9}$ fluoresceines, ${ }^{10}$ and the unique azaoxa-triangulenium dyes. ${ }^{2,3}$ Whereas the former have donor groups on the periphery of the aromatic system contributing to the chromophore properties of the dyes, the latter has the chromophore restricted to the triangulenium core. This gives the azaoxa-triangulenium dyes distinctive photophysical properties, such as a long fluorescence lifetime $\left(\tau_{\mathrm{fl}}>20 \mathrm{~ns}\right)$ despite emission in the red. ${ }^{11-14}$ Triangulenium dyes with only aza bridges and with thio bridges have also been prepared. ${ }^{15-18}$ These have found use in molecular electronics, ${ }^{19-21}$ but their dye properties make them less interesting for applications based on fluorescence.

The azaoxa-triangulenium dyes are cationic fluorophores, where the most relevant are azadioxatriangulenium (ADOTA) and diazaoxatriangulenium (DAOTA). ${ }^{12,14}$ The molecular structures of ADOTA and DAOTA are shown in Scheme 1. The dyes can be prepared with a variety of groups on the aza bridges and with various counter ions $\left(\mathrm{X}^{-}\right){ }^{22}$ The long
Scheme 1. Molecular Structures of ADOTA and DAOTA ${ }^{a}$
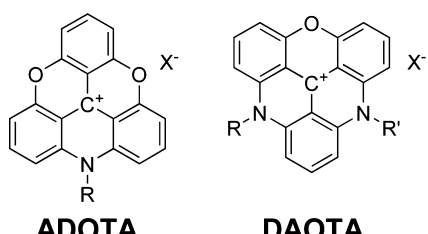

DAOTA

${ }^{a} \mathrm{X}^{-}$is the anion.

fluorescence lifetime of these dyes has been exploited in timeresolved imaging, polarization-based experiments, and metalenhanced fluorescence, ${ }^{23-33}$ and the dyes have been used in bioimaging. ${ }^{34-36}$ Through our experiments with ADOTA and DAOTA, we became aware that the reported fluorescence quantum yields are most likely too low. Thus, we decided to reexamine the fundamental photophysical properties of these dyes to establish a better foundation onto which future applications could be built.

Here, the photophysical properties of three ADOTA derivatives and three DAOTA derivatives are investigated in

Received: August 26, 2016

Accepted: January 6, 2017

Published: January 24, 2017 
acetonitrile $(\mathrm{MeCN})$ and dichloromethane (DCM). Deactivation of the first excited singlet state $\left(S_{1}\right)$ was characterized using steady-state and time-resolved fluorescence spectroscopy. Deactivation via the triplet manifold was investigated using low-temperature spectroscopy and transient absorption spectroscopy and monitoring the sensitized formation of singlet oxygen. Computations were used to support the spectroscopic measurements, to investigate the excited state molecular structure and to map the excited state manifold of ADOTA and DAOTA. The computational results showed that the structural difference between the ground-state $\left(S_{0}\right)$ equilibrium structure and the first singlet excited state $\left(S_{1}\right)$ equilibrium structure has a pronounced effect on the photophysical properties observed for ADOTA and DAOTA.

We conclude that the substitution of the nitrogen bridges in the azaoxa-triangulenium systems has a minor influence on the fluorescence properties, with average quantum yields of fluorescence $\left(\phi_{\mathrm{fl}}\right)$ for ADOTA and DAOTA in air-saturated $\mathrm{MeCN}$ of $\phi_{\mathrm{fl}}(\mathrm{ADOTA})=0.67 \pm 0.03$ and $\phi_{\mathrm{fl}}(\mathrm{DAOTA})=0.55$ \pm 0.04 for a series of three different substitution patterns. In $\mathrm{DCM}$, the average fluorescence quantum yield increases to $\phi_{\mathrm{fl}}(\mathrm{ADOTA})=0.82 \pm 0.01$ and $\phi_{\mathrm{fl}}(\mathrm{DAOTA})=0.78 \pm 0.02$ and is further increased when the solution is saturated with nitrogen $\left[\phi_{\mathrm{fl}}^{\mathrm{N}_{2}}(\mathrm{ADOTA})=0.88 \pm 0.04\right.$ and $\phi_{\mathrm{fl}}^{\mathrm{N}_{2}}(\mathrm{DAOTA})=$ $0.85 \pm 0.04]$. Our study indicates that all deactivation pathways from the first excited singlet state $\left(S_{1}\right)$ of these azaoxatriangulenium dyes are slower than that observed in common cationic dyes. We find that quenching by molecular oxygen and intersystem crossing are the dominant processes that compete with spontaneous emission. However, because quenching by molecular oxygen is comparatively inefficient for these electrondeficient systems, the result is a high quantum yield and long lifetime of fluorescence despite a low oscillator strength and the accompanying slow rate of spontaneous emission.

\section{METHODS AND MATERIALS}

Dyes and Solvents. All chemicals were used as received. All solvents used for spectroscopic experiments were of highperformance liquid chromatography (HPLC) grade and used as received. The dyes used were of analytical grade $(99+\%$ by HPLC monitored at $250 \mathrm{~nm}$ ). The following salts were used: $\mathrm{N}$-methyl-azadioxatriangulenium hexafluorophosphate (MeADOTA, $\mathrm{R}=\mathrm{CH}_{3}, \mathrm{X}^{-}=\mathrm{PF}_{6}$, Scheme 1), N-propylazadioxatriangulenium hexafluorophosphate (PrADOTA, $\mathrm{R}=$ $n-\mathrm{C}_{3} \mathrm{H}_{7}, \mathrm{X}^{-}=\mathrm{PF}_{6}$, Scheme 1), N-phenyl-azadioxatriangulenium tetrafluoroborate (PhADOTA, $\mathrm{R}=\mathrm{C}_{6} \mathrm{H}_{5}, \mathrm{X}^{-}=\mathrm{BF}_{4}^{-}$, Scheme 1), $N, N^{\prime}$-dimethyl-diazaoxatriangulenium hexafluorophosphate (MeDAOTA, $\mathrm{R}=\mathrm{R}^{\prime}=\mathrm{CH}_{3}, \mathrm{X}^{-}=\mathrm{PF}_{6}^{-}$, Scheme 1), N,N'dipropyl-diazaoxatriangulenium hexafluorophosphate (PrDAOTA, $\mathrm{R}=\mathrm{R}^{\prime}=n-\mathrm{C}_{3} \mathrm{H}_{7}, \mathrm{X}^{-}=\mathrm{PF}_{6}^{-}$, Scheme 1), and $N, N^{\prime}-$ diphenyl-diazaoxatriangulenium hexafluorophosphate (PhDAOTA, $\mathrm{R}=\mathrm{R}^{\prime}=\mathrm{C}_{6} \mathrm{H}_{5}, \mathrm{X}^{-}=\mathrm{PF}_{6}^{-}$, Scheme 1). The compounds were synthesized as previously reported., ${ }^{2,3,17}$ MeDAOTA and PhDAOTA are new compounds, and their synthesis and characterization are included in the Supporting Information.

Spectroscopy. Absorption, excitation and emission spectra, fluorescence quantum yields, and lifetimes were measured and determined using standard procedures. Fluorescence spectra were recorded using an L-configuration fluorimeter (PTI QuantaMaster300 and FluoTime300 from PicoQuant). Emission and excitation spectra were corrected using the factory supplied correction files for system response (monochromator, polarizers, and detector), and illumination source fluctuations were corrected using an internal photodiode for the excitation spectra. Absorption spectra were recorded using a Lambda 1050 double-beam spectrophotometer from Perkin-Elmer using the pure solvent as a reference. Time-gated emission spectra were recorded using an LS55B luminescence spectrometer from Perkin-Elmer, equipped with a liquid nitrogen bath cryostat. For all fluorescence measurements, the absorbance at the excitation wavelength and at longer wavelengths was kept below 0.1 to avoid inner filter effects. All fluorescence experiments at ambient temperatures were performed in $10.00 \mathrm{~mm}$ Hellma quartz fluorescence cuvettes. Experiments performed in oxygen- and nitrogen-saturated solutions were performed by saturating the solutions with pure gases. The gases were not saturated with solvent before use. The concentration changes due to the evaporation of solvents were corrected by recording the absorption spectrum of all solutions; see Figures S50-S57.

For the steady-state fluorescence measurements, the dyes were excited at $507 \mathrm{~nm}$ using a solid-state laser-excitation source (LDH-P-C-510 from PicoQuant), and fluorescence spectra were recorded at magic angle settings. Fluorescence quantum yields were determined by a relative method using eq 1 , with rhodamine $6 \mathrm{G}$ in absolute ethanol as standard $\left(\phi_{\mathrm{fl}}=\right.$ $0.95 \pm 0.015){ }^{37,38}$ All emission spectra were corrected for the wavelength-dependent response of the detection system before use in the fluorescence quantum yield determinations. The fluorescence quantum yields were finally determined from the slopes of the linear fits $(\Delta)$, when the integrated fluorescence intensity $(I)$ was plotted as a function of the fraction of absorbed light $\left(f_{\mathrm{A}}\right.$, see eq 2$) .^{38}$ All quantum yield plots are shown in the Supporting Information.

$$
\begin{aligned}
\phi_{\mathrm{fl}} & =\phi_{\mathrm{fl}}(\text { ref }) \times \frac{n_{\mathrm{d}}{ }^{2}}{n_{\mathrm{d}}{ }^{2}(\text { ref })} \times \frac{I}{I(\text { ref })} \times \frac{f_{\mathrm{A}}(\text { ref })}{f_{\mathrm{A}}} \\
& =\phi_{\mathrm{fl}}(\text { ref }) \times \frac{n_{\mathrm{d}}{ }^{2}}{n_{\mathrm{d}}{ }^{2}(\text { ref })} \times \frac{\Delta}{\Delta(\text { ref })} \\
f_{\mathrm{A}} & =1-10^{-A}
\end{aligned}
$$

Demas/Crosby correction: refractive index correction is required to compare $k_{\mathrm{f}}$ determined in different solvents, as the radiative rate constant is derived from an intensity-based experiment. ${ }^{39,40}$ A correction related to the specific geometry of the spectrometer, primarily to compensate for refraction at the sample-air interface, is required to make intensity-based results in general $\left(n_{\mathrm{d}}{ }^{2}\right.$ correction was used here $){ }^{39}$

Fluorescence lifetimes were measured using a hybrid-PMT detector (HPD-06 from PicoQuant) with a spectral range of 200-670 nm using a FluoTime300 system from PicoQuant and pulsed laser diode excitation (450/470/507 $\mathrm{nm})$. The instrument-response function was recorded at the excitation wavelength using a dilute solution of Ludox. The fluorescence decays were analyzed using the FluoFit Professional software package. The decay data were all found to be monoexponential and were fitted by iterative reconvolution with a single exponential function. For all fits, $\chi^{2} \leq 1.1$. All time-resolved emission decay profiles and fits are shown in the Supporting Information.

The time-gated emission spectra were recorded in nitrogensaturated solutions in $\mathrm{MeCN}$ and DCM at room temperature. 
Further time-gated emission spectra and steady-state fluorescence spectra were recorded in methanol, EPA (diethylether/pentane/ethyl alcohol), and MeTHF (rac-2-methyltetrahydrofurane) glasses at $77 \mathrm{~K}$. No emission that could be assigned to the triplet state could be detected.

The equipment and methods used to determine singlet oxygen, $\mathrm{O}_{2}\left(\mathrm{a}^{1} \Delta_{\mathrm{g}}\right)$, quantum yields, and $\phi_{\Delta}$, have been described in detail previously. ${ }^{41-43}$ Briefly, the dyes were excited using femtosecond laser pulses centered at $417 \mathrm{~nm}$, and the photosensitization of $\mathrm{O}_{2}\left(\mathrm{a}^{1} \Delta_{\mathrm{g}}\right)$ was followed via its characteristic phosphorescence signal at $\sim 1275 \mathrm{~nm}$, which was isolated using a $1064 \mathrm{~nm}$ long pass filter and a 1290:80 nm band pass filter placed in front of a near-IR-sensitive PMT detector. For $\mathrm{MeCN}$ solutions, the time-resolved signals were fitted to a single exponential decay function, whereas a fit based on the difference between two exponential functions was needed to describe the signals obtained from DCM solutions owing to a short $(\sim 1 \mu \mathrm{s})$ rise in the signal. ${ }^{44}$ For all samples, the lifetime of $\mathrm{O}_{2}\left(\mathrm{a}^{1} \Delta_{\mathrm{g}}\right)$ retrieved from the fits in the respective solvents $\left[\tau_{\Delta}(\mathrm{DCM})=95 \pm 1 \mu \mathrm{s}\right.$ and $\left.\tau_{\Delta}(\mathrm{MeCN})=79 \pm 2 \mu \mathrm{s}\right]$ coincided with what is expected based on published data. ${ }^{45,46}$ [Note that methanol-stabilized DCM was used for the $\mathrm{O}_{2}\left(\mathrm{a}^{1} \Delta_{\mathrm{g}}\right)$ measurements to avoid photosensitization and/or quenching by other stabilizers commonly used. ${ }^{47}$ ] The integrated intensities of the singlet oxygen phosphorescence signals were determined as a function of incident laser power and compared to the corresponding data from a reference sample: singlet oxygen produced by the sensitizer phenalenone $\left[\phi_{\Delta}(\mathrm{DCM})=0.96 \pm 0.08 \text { and } \phi_{\Delta}(\mathrm{MeCN})=1.00 \pm 0.03\right]^{48}$

Transient absorption experiments were performed with the same femtosecond-laser excitation source at $417 \mathrm{~nm}$ and detection in the range of $\sim 500-880 \mathrm{~nm}$ using a previously described setup. ${ }^{49}$ Using this setup, we were not able to detect any long-lived transient absorption signal (lifetime $>100 \mathrm{~ns}$ ) that could be assigned to triplet-triplet absorption. However, we did observe a short-lived negative absorption signal (lifetime $<100 \mathrm{~ns}$ ) that we assign to the combined effect of $S_{1}$ bleaching and fluorescence.

Computational Chemistry. The photophysical properties were also investigated through computations. Excitation energies and transition dipole moments (TDMs) of the most important singlet transitions of MeADOTA were computed with TD-DFT ${ }^{50-52}$ and three commonly used density functionals. The results were benchmarked with generally more reliable coupled cluster and multireference multiconfigurational calculations. The functionals that performed the best were applied while calculating the electronic transitions of PhADOTA, MeDAOTA, and PhDAOTA as well. All calculations were performed considering the molecules in vacuo.

The hybrid density functional $\mathrm{B} 3 \mathrm{LYP},{ }^{53}$ its long-range corrected version CAM-B3LYP, ${ }^{54}$ and the hybrid density functional M06 ${ }^{55}$ were tested. The B3LYP and M06 functionals have been shown to be excellent for calculations of excitation energies in several TD-DFT benchmark studies. ${ }^{56-59}$ CAMB3LYP was chosen for a potential improvement over B3LYP. ${ }^{60-62}$ Furthermore, the CC2 method $^{63}$ was used as the coupled cluster reference because it has been shown that CC2 tends to reproduce CC3 excitation energies better than CCSD. ${ }^{64-67}$ In all calculations, Dunning's correlation-consistent basis sets ${ }^{68}$ were used. ${ }^{69}$ The cardinal numbers of the basis sets were increased until the results showed sufficient convergence. Finally, MS-RASPT2//SA-RASSCF was used as reference for an advanced multiconfigurational method. ${ }^{70-73}$ These calculations used an ANO-RCC-PVTZ basis set, ${ }^{71,74}$ default Choleski decomposition, ${ }^{75}$ default IPEA shift 0.25 , $^{76}$ an imaginary shift value of $0.1,77$ and an active space comprising 10 orbitals in RAS1, 4 orbitals in RAS2, 8 orbitals in RAS3, 24 active electrons, and 2 or 3 holes/excitations in RAS1/3 (denoted later as $\mathrm{PT} 2-2 \mathrm{HE}$ and $\mathrm{PT} 2-3 \mathrm{HE}$, respectively). Different numbers of deleted virtual orbitals were also tested for the convergence of the results.

The CC2 and B3LYP calculations were performed using the TURBOMOLE 6.5 program. $^{78}$ For evaluation of the twoelectron integrals, the resolution of the identity method (RI) was applied with auxiliary basis sets from the TURBOMOLE library. ${ }^{79}$ The frozen core approximation was used in the coupled cluster computations. The calculations with CAMB3LYP and M06 were performed using Gaussian 09. ${ }^{80,81}$ The PT2-2HE and PT2-3HE calculations were performed using MOLCAS version 7.8.

According to the Franck-Condon principle, the excitation energies and TDMs of the absorption processes were calculated using the calculated equilibrium structure of the ground states. To analyze the properties of the fluorescence and phosphorescence processes, the structures were optimized without symmetry constraints in their first excited singlet and triplet states, respectively. Due to the computational cost of MSRASPT2 calculations, geometry-optimized structures obtained at the B3LYP/cc-pVTZ level of theory were used when computing $\mathrm{PT} 2-2 \mathrm{HE}$ and $\mathrm{PT} 2-3 \mathrm{HE}$ reference excitation energies.

As a result of the benchmark study, the values reported were obtained by the following approach: B3LYP/cc-pVTZ was used for geometry optimizations, whereas the transition energies were calculated for the larger cc-pVQZ basis set. For all geometry optimizations, the validity of the results was confirmed by the absence of the imaginary vibrational frequencies; see the Supporting Information for details. The singlet TDMs were computed by the application of CAMB3LYP/cc-pVQZ. The oscillator strengths were calculated from B3LYP energies and CAM-B3LYP TDMs.

Excited State Kinetics. The nomenclature used follows that of textbooks on fluorescence. The relationship between the determined fluorescence quantum yield $\left[\phi_{\mathrm{fl}}=k_{\mathrm{f}} /\left(k_{\mathrm{f}}+k_{\mathrm{nr}}\right)\right]$ and the observed fluorescence lifetime $\left[\tau_{\mathrm{fl}}=1 / k_{\mathrm{obs}}=1 /\left(k_{\mathrm{f}}+k_{\mathrm{nr}}\right)\right]$ described in eq 3 can be used to determine $k_{\mathrm{f}}$, the fluorescence rate constant, and $k_{\mathrm{nr}}$, the rate constant for nonradiative depopulation of $S_{1}$. The fluorescence rate constant $k_{\mathrm{f}}$ is also called the radiative rate constant and is the reciprocal of the radiative lifetime $\tau_{0}=1 / k_{\mathrm{f}}$. The error in determining these rate constants is dominated by the error in the quantum yield determination.

$$
\phi_{\mathrm{fl}}=\frac{k_{\mathrm{f}}}{k_{\mathrm{obs}}}=\frac{\tau_{\mathrm{fl}}}{\tau_{0}}
$$

The nonradiative depopulation of the first excited state $S_{1}$ occurs via two unimolecular processes: internal conversion to the ground state $\left(\mathrm{S}_{0}\right)$ described by the rate of internal conversion $k_{\mathrm{ic}}$ and intersystem crossing to the triplet manifold occurring with the rate constant $k_{\text {isc }}^{\mathrm{S} \rightarrow \mathrm{T}}$. If there are molecular quenchers present, bimolecular terms must be included. Of importance in our case is quenching by molecular oxygen $k_{\mathrm{O}_{2}}\left[\mathrm{O}_{2}\right]$. Equation 4 shows the relationship between the fluorescence lifetime $\tau_{\mathrm{fl}}$ and $k_{\mathrm{obs}}$, the observed rate constant 
for the depopulation of $S_{1}$. The latter is the sum of all rate constants depopulating $S_{1}$

$$
\frac{1}{\tau_{\mathrm{fl}}}=k_{\mathrm{obs}}=k_{\mathrm{f}}+k_{\mathrm{nr}}=k_{\mathrm{f}}+k_{\mathrm{ic}}+k_{\mathrm{isc}}^{\mathrm{S} \rightarrow \mathrm{T}}+k_{\mathrm{O}_{2}}\left[\mathrm{O}_{2}\right]
$$

In eq 4 , the oxygen-dependent processes are described by a single rate constant, even though the interaction of oxygen with the singlet excited state $\left(S_{1}\right)$ may occur through multiple pathways (i.e., oxygen-induced intersystem crossing: $S_{1} \rightarrow T_{1}$ and internal conversion: $\left.S_{1} \rightarrow S_{0}\right){ }^{83-85}$

\section{RESULTS AND DISCUSSION}

The electronic transitions in ADOTA and DAOTA have previously been investigated using optical spectroscopy. ${ }^{3,12,14,23,33}$ All observed transitions are related to the singlet manifold of the two dyes, which implies that all transition dipoles are in the plane of the molecules, ${ }^{12}$ as the symmetry of the chromophore core is $C_{2 v}$. The primary transitions $\left(S_{0} \rightarrow S_{1}\right)$ of ADOTA and DAOTA are to the states of ${ }^{1} \mathrm{~A}_{1}$ and the ${ }^{1} \mathrm{~B}_{2}$ symmetries, respectively, whereas the symmetries are reversed for the second transition $\left(\mathrm{S}_{0} \rightarrow \mathrm{S}_{2}\right)$ with ${ }^{1} \mathrm{~B}_{2}$ and ${ }^{1} \mathrm{~A}_{1}$ for ADOTA and DAOTA. ${ }^{12}$ In the molecular structure, this is related to the position of the nitrogen donor atoms, where the primary transition dipole moment is on the axis of the molecule containing the nitrogen donor atom(s). Optical transitions between the triplet and singlet states, such as phosphorescence, are spin forbidden. We have previously not been able to observe direct triplet absorption or phosphorescence by applying the commonly used methods. ${ }^{86}$ Figure 1 shows the

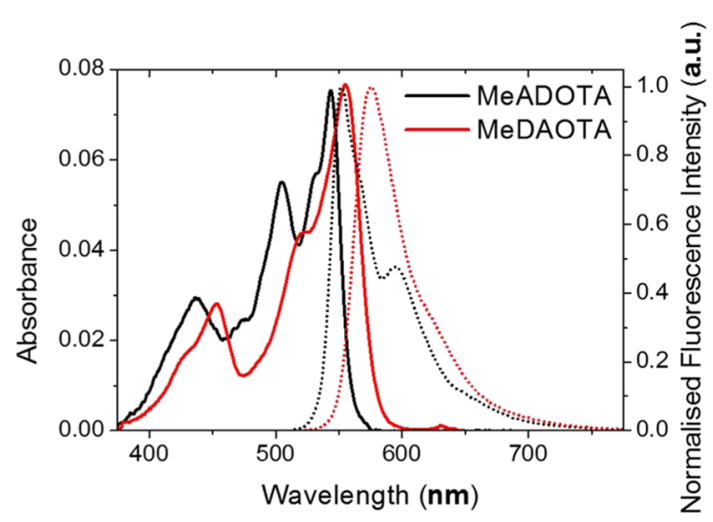

Figure 1. For $N$-methyl-azadioxatriangulenium hexafluorophosphate (MeADOTA) and $N, N^{\prime}$-dimethyl-diazaoxatriangulenium hexafluorophosphate (MeDAOTA) in DCM.

two lowest energy transitions in the absorption spectra and the fluorescence spectra of MeADOTA and MeDAOTA. The transitions in DAOTA are red-shifted compared with ADOTA, with $\lambda_{\max }($ ADOTAIDCM $)=543 \mathrm{~nm} / \lambda_{\max }($ DAOTAIDCM $)=$ $555 \mathrm{~nm}$ and $\lambda_{\mathrm{fl}}($ ADOTAIDCM $)=552 \mathrm{~nm} / \lambda_{\mathrm{fl}}($ DAOTAIDCM $)$ $=574 \mathrm{~nm}$. This is a direct consequence of the higher donor strength of nitrogen compared with that of oxygen. ${ }^{87,88}$ The stronger donor groups in DAOTA also result in a larger oscillator strength in this system. ${ }^{12}$ The unique feature of the azaoxa-triangulenium dyes is a long fluorescence lifetimes $\left(\tau_{\mathrm{fl}} \geq\right.$ $20 \mathrm{~ns})$. The question remains as to why the nonradiative processes from $S_{1}$ (described by $k_{\mathrm{nr}}$ ) are so slow that the radiative process $\left(k_{\mathrm{f}}\right)$ becomes the dominating process for deactivating $S_{1}$.
We started the investigation by recording the absorption and fluorescence spectra for three derivatives of ADOTA and three derivatives of DAOTA in MeCN and DCM. For all derivatives, varying only the substituents on nitrogen, the absorption spectra and the fluorescence excitation spectra are found to be close to identical and the emission spectra are similar; see Figures S1-S12. Two low energy transitions of intermediate intensity $\left(5000<\varepsilon<20000 \mathrm{M}^{-1} \mathrm{~cm}^{-1}\right)$ are observed for the chromophores in the visible part of the spectrum (Figure 1), whereas high-intensity localized transitions can be observed in the UV region of the spectrum. ${ }^{12}$ The fluorescence emission appears to obey both the mirror image rule and Kasha's rule (i.e., fluorescence occurs exclusively from the first excited singlet state; see the Supporting Information). ${ }^{89,90}$ It is worth to note the more detailed vibrational progression that can be observed in DCM compared with MeCN. In general, DCM is the best solvent for studying cationic dyes without interference from solvent effects or ion pairing. ${ }^{91,92} \mathrm{MeCN}$ is a very good solvent for solubilizing triangulenium ions, a consequence of the strong solvent-solute interaction. In the spectra, this can be seen as a significant reduction in the vibrational fine structure (see the Supporting Information).

Fluorescence Quantum Yield Determination. In the initial phase of the studies reported here, we compared the results obtained using uncalibrated, factory calibrated, and experimentally calibrated from two different fluorimeters using a Hamamatsu R928 detector. While performing this calibration, and in our previous work, we used several standards such as rhodamine 101 , rhodamine $\mathrm{B}$, and rhodamine $6 \mathrm{G}$. Here, we chose to use rhodamine $6 \mathrm{G}\left(\phi_{\mathrm{fl}}=0.95 \pm 0.015\right)$ in absolute ethanol as the standard. ${ }^{33,34}$ The IUPAC-recommended fluorescence quantum yield standards all have spectra on the blue side of the ADOTA and DAOTA emissions, yet rhodamine $6 \mathrm{G}$ in ethanol has the same emission maximum as ADOTA; see Figure 2. ${ }^{37}$ The reported fluorescence quantum

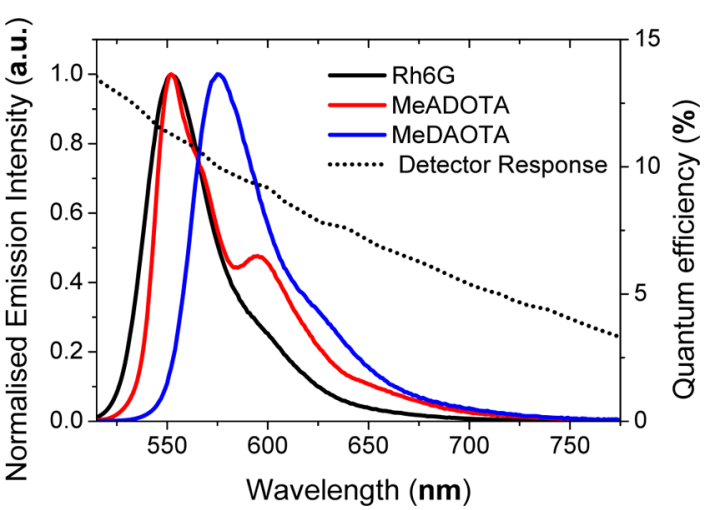

Figure 2. Normalized fluorescence emission spectra of rhodamine 6G (Rh6G, abs ethanol), N-methyl-azadioxatriangulenium hexafluorophosphate (MeADOTA, DCM), N,N'-dimethyl-azadioxatriangulenium hexafluorophosphate (MeDAOTA, DCM), and the quantum efficiency specified for a Hamamatsu R928 photomultiplier tube.

yields $\left(\phi_{\mathrm{fl}}\right)$ for ADOTA and DAOTA in air-saturated $\mathrm{MeCN}$ are 0.42 and $0.46,{ }^{12-14}$ and the fluorescence quantum yields determined in the present study are significantly larger than what was previously reported; see Table 1 and the Supporting Information. In $\mathrm{MeCN}$, we find average quantum yields of fluorescence over the three derivatives of $\phi_{\mathrm{fl}}(\mathrm{ADOTA})=0.68$ \pm 0.04 and $\phi_{\mathrm{fl}}(\mathrm{DAOTA})=0.58 \pm 0.03$. We assume that this discrepancy between our present data and published values can 
Table 1. Fluorescence Quantum Yields $\phi_{\mathrm{fl}}$, Fluorescence Lifetimes $\tau_{\mathrm{ff}}$, Radiative Lifetimes $\tau_{0}$, Radiative Rate Constant $k_{\mathrm{f}}$, and Nonradiative Rate Constant $k_{\mathrm{nr}}$ for the Deactivation of Singlet State of Azadioxatriangulenium ADOTA and Diazaoxatriangulenim DAOTA in Nitrogen-Saturated $\left(\mathrm{N}_{2}\right)$, Air-Saturated (Air), and Oxygen-Saturated $\left(\mathrm{O}_{2}\right)$ Solutions ${ }^{a}$

\begin{tabular}{|c|c|c|c|c|c|c|}
\hline & \multicolumn{3}{|c|}{ ADOTA } & \multicolumn{3}{|c|}{ DAOTA } \\
\hline & methyl- & propyl- & phenyl- & dimethyl- & dipropyl- & diphenyl- \\
\hline \multicolumn{7}{|c|}{ Dichloromethane } \\
\hline$\phi_{\mathrm{fl}}^{\mathrm{N}_{2} b}$ & & 0.90 & 0.86 & & 0.87 & 0.83 \\
\hline$\phi_{\mathrm{fl}}^{\mathrm{air} b}$ & 0.83 & 0.83 & 0.81 & 0.76 & 0.80 & 0.76 \\
\hline$\phi_{\mathrm{fl}}^{\mathrm{O}_{2} b}$ & & 0.70 & 0.66 & & 0.59 & 0.54 \\
\hline$\tau_{\mathrm{fl}}^{\mathrm{N}_{2}}(\mathrm{~ns})$ & & 24.1 & 23.0 & & 22.4 & 21.2 \\
\hline$\tau_{\mathrm{fl}}^{\mathrm{air}}(\mathrm{ns})$ & 23.5 & 23.2 & 22.0 & 22.2 & 21.3 & 20.0 \\
\hline$\tau_{\mathrm{fl}}^{\mathrm{O}_{2}}(\mathrm{~ns})$ & & 19.4 & 18.4 & & 17.1 & 15.7 \\
\hline$\tau_{0}^{\text {average }}(\mathrm{ns})$ & 28.3 & 27.9 & 27.2 & 29.1 & 26.5 & 26.5 \\
\hline$k_{\mathrm{f}}^{\mathrm{N}_{2}}\left(10^{8} \mathrm{~s}^{-1}\right)$ & & 0.37 & 0.38 & & 0.39 & 0.39 \\
\hline$k_{\mathrm{f}}^{\mathrm{air}}\left(10^{8} \mathrm{~s}^{-1}\right)$ & 0.35 & 0.36 & 0.37 & 0.34 & 0.38 & 0.38 \\
\hline$k_{\mathrm{f}}^{\mathrm{O}_{2}}\left(10^{8} \mathrm{~s}^{-1}\right)$ & & 0.36 & 0.36 & & 0.38 & 0.43 \\
\hline$k_{\mathrm{f}}^{\mathrm{air}} / n^{3}\left(10^{8} \mathrm{~s}^{-1}\right)^{c}$ & 0.12 & 0.13 & 0.13 & 0.12 & 0.13 & 0.13 \\
\hline$k_{\mathrm{nr}}^{\mathrm{air}}\left(10^{8} \mathrm{~s}^{-1}\right)$ & 0.07 & 0.07 & 0.09 & 0.11 & 0.09 & 0.12 \\
\hline$\phi_{\Delta}^{\mathrm{air} d}$ & 0.08 & 0.08 & 0.07 & 0.08 & 0.09 & 0.07 \\
\hline$\phi_{\text {total }}^{\text {air } e}$ & 0.91 & 0.91 & 0.88 & 0.84 & 0.89 & 0.83 \\
\hline \multicolumn{7}{|c|}{ Acetonitrile } \\
\hline$\phi_{\mathrm{fl}}^{\mathrm{N}_{2} b}$ & & 0.77 & 0.79 & & 0.65 & 0.65 \\
\hline$\phi_{\mathrm{fl}}^{\mathrm{air} b}$ & 0.64 & 0.69 & 0.68 & 0.51 & 0.58 & 0.57 \\
\hline$\phi_{\mathrm{fl}}^{\mathrm{O}_{2} b}$ & & 0.53 & 0.53 & & 0.43 & 0.40 \\
\hline$\tau_{\mathrm{fl}}^{\mathrm{N}_{2}}(\mathrm{~ns})$ & & 24.9 & 23.7 & & 22.5 & 20.6 \\
\hline$\tau_{\mathrm{fl}}^{\mathrm{air}}(\mathrm{ns})$ & 23.3 & 22.9 & 21.7 & 19.7 & 20.1 & 17.4 \\
\hline$\tau_{\mathrm{fl}}^{\mathrm{O}_{2}}(\mathrm{~ns})$ & & 17.7 & 14.5 & & 14.5 & 13.0 \\
\hline$\tau_{0}^{\text {average }}(\mathrm{ns})$ & 36.3 & 33.2 & 32.1 & 38.4 & 34.7 & 30.3 \\
\hline$k_{\mathrm{f}}^{\mathrm{N}_{2}}\left(10^{8} \mathrm{~s}^{-1}\right)$ & & 0.31 & 0.33 & & 0.29 & 0.31 \\
\hline$k_{\mathrm{f}}^{\mathrm{air}}\left(10^{8} \mathrm{~s}^{-1}\right)$ & 0.28 & 0.30 & 0.31 & 0.26 & 0.26 & 0.29 \\
\hline$k_{\mathrm{f}}^{\mathrm{O}_{2}}\left(10^{8} \mathrm{~s}^{-1}\right)$ & & 0.30 & 0.37 & & 0.29 & 0.31 \\
\hline$k_{\mathrm{f}}^{\mathrm{air}} / n^{3}\left(10^{8} \mathrm{~s}^{-1}\right)^{c}$ & 0.11 & 0.13 & 0.13 & 0.11 & 0.12 & 0.14 \\
\hline$k_{\mathrm{nr}}^{\mathrm{air}}\left(10^{8} \mathrm{~s}^{-1}\right)$ & 0.15 & 0.14 & 0.15 & 0.25 & 0.21 & 0.24 \\
\hline$\phi_{\Delta}^{\mathrm{air} d}$ & 0.12 & 0.12 & 0.11 & 0.11 & 0.11 & 0.13 \\
\hline$\phi_{\text {total }}^{\text {air } e}$ & 0.76 & 0.81 & 0.79 & 0.62 & 0.69 & 0.70 \\
\hline
\end{tabular}

${ }^{a}$ We estimate the error of the derived quantities to be less than $10 \% .{ }^{b}$ Measured using rhodamine $6 \mathrm{G}$ in absolute ethanol as the standard $\left(\phi_{\mathrm{fl}}=0.95\right.$ $\pm 0.015)$ following $507 \mathrm{~nm}$ laser excitation. ${ }^{c}$ Refractive indices used: $n_{\mathrm{d}}(\mathrm{MeCN})=1.341 ; n_{\mathrm{d}}{ }^{3}=2.411 ; n_{\mathrm{d}}(\mathrm{DCM})=1.421 ; n_{\mathrm{d}}{ }^{3}=2.869$, correction chosen following refs 93 and 94, that is, a partial conversion from rate constant to transition dipole moment. ${ }^{d}$ Quantum yield of singlet oxygen formation. ${ }^{e}$ Total experimentally determined depopulation of $S_{1}, \phi_{\text {tot }}=\phi_{\mathrm{fl}}+\phi_{\Delta}$.

be due to incorrect detector calibration in the earlier studies and underestimation of the fluorescence quantum yield of the standards used. ${ }^{12-14}$ The quantum efficiency of the popular R928 detector from Hamamatsu is included in Figure 2 and drops significantly toward the higher red wavelengths. If an incorrect detector calibration is used, this will lead to an underestimation of the recorded emission intensity.

Excited State Kinetics. With accurate fluorescence quantum yields $\phi_{\mathrm{fl}}$, the fluorescence lifetimes $\tau_{\mathrm{fl}}$ can be used to calculate the radiative lifetime of $S_{1}, \tau_{0}$, and thus the fluorescence rate constant $k_{\mathrm{f}}$; see eq 3 . The radiative lifetimes were calculated for all six azaoxatriangulenium derivatives in $\mathrm{MeCN}$ and DCM, and the results are listed in Table 1. When the fluorescence rate constants are corrected for the refractive indices of the solvents, ${ }^{94}$ the obtained values of $k_{\mathrm{f}}$ are, within our error limits, identical for all six fluorescent dyes. Thus, the transition dipole moment responsible for the emission must be of similar magnitude for these six fluorophores. This implies that the rate constant describing the radiative transition is independent of the number of donor nitrogen atoms in the triangulenium core and the substituents on the donor nitrogens.

The observed differences in the fluorescence quantum yields must be mainly due to differences in the nonradiative deactivation described by the nonradiative rate constant $k_{\mathrm{nr}}$ that can be calculated using eq 4; see Table 1. Although no difference in $k_{\mathrm{nr}}$ is observed for ADOTA and DAOTA as a function of substituents on the aza bridges, there is a significant difference between solvents. In $\mathrm{MeCN}$, values of $k_{\mathrm{nr}}$ are roughly two times larger than the corresponding values found in DCM. We propose that coupling to the solvent bath is more efficient in $\mathrm{MeCN}$, but as no difference in $k_{\mathrm{nr}}$ is seen between derivatives with significantly different substituents, a simple explanation along the "loose-bolt" principle can be excluded. ${ }^{95}$ The high fluorescence quantum yields (>80\%) in air-saturated DCM indicate that nonradiative processes (described by $k_{\mathrm{nr}}$ ) are inefficient $(<20 \%)$ in the azaoxa-triangulenium dyes. When compared with common organic fluorophores (Table 2), it is 
Table 2. Photophysical Parameters of Selected Organic Fluorophores under Air-Saturated Conditions: The Fluorescence Rate Constant $k_{\mathrm{f}}$, the Nonradiative Rate Constant $k_{\mathrm{nr}}$, the Rate Constant for Oxygen Quenching $k_{\mathrm{O}_{2}}$, the Fluorescence Quantum Yield $\phi_{\mathrm{fl}}$, and the Fluorescence Lifetime $\tau_{\mathrm{fl}}$

\begin{tabular}{|c|c|c|c|c|c|c|}
\hline & $k_{\mathrm{f}}^{a} 10^{8} \mathrm{~s}^{-1}$ & $k_{\mathrm{nr}}^{b} 10^{8} \mathrm{~s}^{-1}$ & $k_{\mathrm{O}_{2}}{ }^{c} 10^{10} \mathrm{M}^{-1} \mathrm{~s}^{-1}$ & $\phi_{\mathrm{fl}}$ & $\tau_{\mathrm{fl}} \mathrm{ns}$ & solvent \\
\hline anthracene $^{d}$ & 0.47 & 1.26 & 2.50 & 0.27 & 5.8 & ethanol \\
\hline perylene $^{d}$ & 1.45 & 0.22 & 2.70 & 0.87 & 6 & ethanol \\
\hline 1,18-di(ethyl propionate)-7,12-diethenyl-3,8,13,17-tetramethyl porphyrin ${ }^{d}$ & 0.03 & 0.40 & 1.80 & 0.06 & 23 & benzene \\
\hline fluorescein $^{d}$ & 2.7 & 0.08 & & 0.97 & 3.6 & $1 \mathrm{M} \mathrm{NaOH}$ \\
\hline Rh6G & 2.3 & 0.37 & & 0.95 & 3.8 & ethanol \\
\hline ADOTA $^{a}$ & 0.36 & 0.08 & 0.09 & 0.83 & 23 & DCM \\
\hline DAOTA $^{e}$ & 0.38 & 0.11 & 0.13 & 0.78 & 21 & DCM \\
\hline
\end{tabular}

${ }^{a}$ Radiative rate constant for fluorescence. ${ }^{b}$ Rate constant determined for nonradiative deactivation of $S_{1} .{ }^{c}$ Rate constant for oxygen-dependent quenching of $S_{1} \cdot{ }^{d}$ From the Handbook of Photochemistry. ${ }^{86}{ }^{e}$ Average values for all azaoxa-triangulenium dyes are investigated here, and the error is estimated to be less than $5 \%$.

worth noting that both the radiative and the nonradiative rate constants depopulating the first excited singlet state of the azaoxa-triangulenium dyes are small.

The low fluorescence rate constant is directly related to the low oscillator strength of the primary transition. For the nonradiative processes contributing to the deactivation of the first-excited singlet state $S_{1}$ of the azaoxa-triangulenium dyes (embodied by $k_{\mathrm{nr}}$ ), we must undertake a detailed analysis.

Investigating Nonradiative Deactivation and the Influence of Oxygen. Internal conversion and intersystem crossing can normally be probed using transient-absorption spectroscopy and time-gated emission spectra. However, we did not manage to record a transient absorption spectrum, over the range $500-880 \mathrm{~nm}$, that could be assigned to a triplet state from nitrogen- and air-saturated solutions of ADOTA and DAOTA. Furthermore, under ambient conditions in nitrogensaturated solutions and in frozen solution at $77 \mathrm{~K}$, we did not observe any phosphorescence using time-gated spectroscopy. Our experiments in various solvents indicate that the previously reported phosphorescence spectrum for trioxatriangulenium arises from a neutral leuco-adduct, not from the cationic triangulenium dye. ${ }^{96}$ Thus, we did not see direct evidence for the formation of a triplet state.

The triplet state of organic dyes may be monitored indirectly by following the generation and subsequent phosphorescence of singlet oxygen, and singlet oxygen was indeed detected following the excitation of ADOTA and DAOTA. The amount of singlet oxygen formed can be determined using a relative method. The singlet-oxygen quantum yields $\left(\phi_{\Delta}\right)$ following the excitation of ADOTA and DAOTA recorded at ambient oxygen concentrations (air-saturated) are included in Table 1. Singlet oxygen is usually formed by energy transfer from the triplet state because this state lives sufficiently long for oxygen to collide with the molecule. However, for these dyes in particular, direct formation of singlet oxygen from $S_{1}$ is also a possibility, owing to the long singlet-state lifetime. ${ }^{84}$ The singlet excited state energy is sufficient to allow for singlet oxygen formation directly; conversely, oxygen-mediated intersystem crossing cannot result in the formation of singlet oxygen as the computed energy gap between $S_{1}$ and $T_{2} / T_{1}$ at $\sim 2000: \sim 5000$ $\mathrm{cm}^{-1}$ is significantly smaller than $\sim 7900 \mathrm{~cm}^{-1}$, which is required to generate singlet oxygen. The observed singlet oxygen emission thus points to the generation of singlet oxygen through the $\mathrm{T}_{1} \rightarrow \mathrm{S}_{0}$ and/or $\mathrm{S}_{1} \rightarrow \mathrm{S}_{0}$ transitions. $^{84,85}$

In DCM, a short rise in the singlet oxygen phosphorescence traces with a lifetime of roughly $1 \mu$ s could be discerned. The kinetics of this rising portion of the signal can be associated with the decay kinetics of the singlet oxygen precursor. ${ }^{44}$ Because this observed microsecond rise time is much longer than the nanosecond lifetime of $S_{1}$ in oxygenated solutions of ADOTA and DAOTA, we infer that singlet oxygen is formed from the triplet state. The quantum yields of singlet oxygen formation account for up to $10 \%$ of the absorbed photons in air-saturated solutions; see Table 1 .

The fluorescence quantum yields and fluorescence lifetimes were determined for all six compounds in DCM and MeCN solutions with varying amounts of dissolved oxygen. This was achieved by investigating solutions of the azaoxa-triangulenium dyes saturated with air, nitrogen, and oxygen. The data can be used to investigate the nonradiative deactivation of $S_{1}$ embodied by $k_{\mathrm{nr}}$, which can be described as a sum of rate constants as done in eq 4 . The nonradiative deactivation of ADOTA and DAOTA depends on the oxygen concentration with the rate constant $k_{\mathrm{O}_{2}}$. It is generally assumed that oxygen quenching of $S_{1}$ produces a triplet state. Nevertheless, the exception can indeed occur as follows: oxygen quenching of $S_{1}$ can result in internal conversion. ${ }^{84}$ Table 2 shows the determined values of $k_{\mathrm{O}_{2}}$ for ADOTA and DAOTA, along with the corresponding rate constants for other selected organic fluorophores. Upon cursory inspection of Table 2, it is evident that the azaoxa-triangulenium dyes do not undergo quenching by oxygen at the diffusion-controlled limit $\left(k_{\text {diff }} \approx 10^{10} \mathrm{M}^{-1}\right.$ $\left.\mathrm{s}^{-1}\right) .{ }^{97}$ Although the observed $k_{\mathrm{O}_{2}}$ for ADOTA and DAOTA is significantly smaller than what is commonly observed for polyaromatic dyes, it is of the same order of magnitude as what has been observed for a series of acridinium and cyanosubstituted dyes with electron-poor $S_{1}{ }^{83,85}$ Thus, our data suggest that the redox properties of ADOTA and DAOTA are not amendable for efficient excited state interactions with molecular oxygen. ${ }^{11,83,85}$

The data in Table 2 show that a small rate constant for nonradiative decay is the reason that the azaoxa-triangulenium dyes have the unique combination of a large fluorescence quantum yield and a long emission lifetime.

Solvent Effects. Comparing MeCN and DCM (Table 1), we infer that strong coupling to the solvent bath induces a more efficient nonradiative deactivation as $k_{\mathrm{nr}}(\mathrm{MeCN}) \approx$ $2 k_{\mathrm{nr}}(\mathrm{DCM})$. However, the observation gives no information regarding the mechanism of nonradiative deactivation via internal conversion (no direct experimental evidence) or intersystem crossing (experimentally observed via singlet oxygen kinetics with a microsecond rise). It is clear that the pathway for nonradiative deactivation is more efficient in 
Table 3. Benchmark Data for the Calculation of Absorption and Fluorescence Energies and TDMs in MeADOTA with Different Methods and Basis Sets, the Error in the Reported Values Are Those Inherent of the Methods Used ${ }^{a}$

\begin{tabular}{|c|c|c|c|c|c|c|c|c|c|c|}
\hline basis set/active space & $\mathrm{CC} 2$ & B3LYP & CAM-B3LYP & M06 & MS-RASPT2 & $\mathrm{CC} 2$ & B3LYP & CAM-B3LYP & M06 & MS-RASPT2 \\
\hline \multicolumn{5}{|c|}{ Absorption Energy $S_{0} \rightarrow S_{1}(e V)$} & & \multicolumn{5}{|c|}{ Fluorescence Energy $S_{1} \rightarrow S_{0}(\mathrm{eV})$} \\
\hline cc-pVDZ & 2.60 & 2.66 & 3.04 & 2.77 & & 2.20 & 2.38 & 2.82 & 2.50 & \\
\hline cc-pVTZ & 2.57 & 2.66 & 3.03 & 2.76 & & 2.24 & 2.37 & 2.80 & 2.49 & \\
\hline cc-pVQZ & 2.56 & 2.65 & 3.02 & 2.76 & & 2.22 & 2.37 & 2.79 & 2.49 & \\
\hline CBS & 2.55 & 2.65 & 3.02 & 2.77 & & 2.21 & 2.37 & 2.79 & 2.48 & \\
\hline cc-pVQZ ${ }^{b}$ & 2.56 & 2.64 & 2.98 & 2.72 & & 2.22 & 2.34 & 2.70 & 2.42 & \\
\hline
\end{tabular}

PT2-2HE

$\mathrm{PT} 2-3 \mathrm{HE}^{\mathrm{c}}$

\begin{tabular}{lccc} 
& \multicolumn{3}{c}{ Absorption TDM (D) } \\
cc-pVDZ & 3.88 & 3.03 & 3.73 \\
cc-pVTZ & 3.79 & 3.01 & 3.69 \\
cc-pVQZ & 3.77 & 3.01 & 3.69 \\
CBS & 3.77 & 3.01 & 3.68 \\
cc-pVQZ $^{b}$ & 3.77 & 3.01 & 3.70 \\
\multicolumn{1}{c}{ PT2-2HE } \\
\multicolumn{1}{c}{ PT2-3HE }
\end{tabular}

\subsection{3}

2.74

$$
\begin{aligned}
& 3.12 \\
& 3.12 \\
& 3.12 \\
& 3.11 \\
& 3.14
\end{aligned}
$$

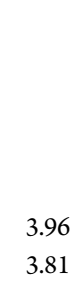

2.37

$\begin{array}{cr}\text { Fluorescence } & \text { TDM }(D) \\ 3.49 & 2.82 \\ 3.44 & 2.81 \\ 3.44 & 2.79 \\ 3.43 & \\ 3.36 & 2.81\end{array}$

3.81

${ }^{a}$ Unless otherwise indicated, geometries of the $S_{0}$ or $S_{1}$ minima were obtained with the corresponding methodology. "CBS" stands for the

\begin{tabular}{|c|c|c|c|c|c|c|c|c|c|c|c|c|}
\hline & \multicolumn{2}{|c|}{$\mathrm{S}_{0} \rightarrow \mathrm{S}_{1}$} & \multicolumn{2}{|c|}{$\mathrm{S}_{0} \rightarrow \mathrm{S}_{2}$} & \multicolumn{2}{|c|}{$\mathrm{S}_{0} \rightarrow \mathrm{T}_{1}$} & \multicolumn{2}{|c|}{$\mathrm{S}_{0} \rightarrow \mathrm{T}_{2}$} & \multicolumn{2}{|c|}{$\mathrm{T}_{1} \rightarrow \mathrm{T}_{2}$} & \multicolumn{2}{|c|}{$\mathrm{T}_{1} \rightarrow \mathrm{T}_{3}$} \\
\hline & $\mathrm{cm}^{-1}$ & $\mathrm{~nm}$ & $\mathrm{~cm}^{-1}$ & $\mathrm{~nm}$ & $\mathrm{~cm}^{-1}$ & $\mathrm{~nm}$ & $\mathrm{~cm}^{-1}$ & $\mathrm{~nm}$ & $\mathrm{~cm}^{-1}$ & $\mathrm{~nm}$ & $\mathrm{~cm}^{-1}$ & $\mathrm{~nm}$ \\
\hline MeADOTA & 21400 & 468 & 23300 & 429 & 16200 & 618 & 19300 & 519 & 3560 & 2810 & 12000 & 831 \\
\hline MeDAOTA & 21000 & 477 & 23100 & 434 & 16100 & 623 & 18600 & 538 & 3460 & 2890 & 12500 & 799 \\
\hline
\end{tabular}
extrapolation of the data to the complete basis set limit; see the Supporting Information. ${ }^{b}$ All energies were calculated with the given methods, and a cc-pVQZ basis set with geometries was optimized with CC2/cc-pVQZ. ${ }^{c}$ All energies were calculated with an ANO-RCC-PVTZ basis set, and geometries were optimized with B3LYP/cc-pVTZ.

Table 4. Calculated Vertical-Transition Energies for the First Excited States in the Singlet and Triplet Manifold ${ }^{a}$

${ }^{a}$ Data are reported in both $\mathrm{cm}^{-1}$ and $\mathrm{nm}$ to facilitate comparison with the experimental data. The error in the reported values for MeDAOTA is 800 $\mathrm{cm}^{-1}$, whereas those for MeADOTA are those inherent of the computational method used (B3LYP/cc-pVQZ).

DAOTA than in ADOTA. As the major difference between the two dyes is the number of aza bridges, we suggest that these are responsible for this difference. It has been speculated that nitrogen atoms in the conjugated system promote intersystem crossing via pyramidalization. ${ }^{98}$ A more efficient pathway for intersystem crossing is consistent with the observed lower fluorescence quantum yields for DAOTA when compared with ADOTA.

In summary, the experimental results implicate the formation of a triplet state, demonstrate that oxygen influences the deactivation of $S_{1}$, and show that we can account for a total of $\sim 90 \%$ of the absorbed photons in air-saturated DCM. Compared with other dyes (Table 2), azaoxa-triangulenium dyes have a low overall rate of nonradiative deactivation of the first excited state $\left(k_{\mathrm{nr}}\right)$ in the air-saturated solution and a low rate of oxygen mediated deactivation $\left(k_{\mathrm{O}_{2}}\right)$. It has to be noted that the discussion has not included molecular quenching. If the quenching of the singlet states of ADOTA and DAOTA occurs via photoinduced electron transfer, the efficiency depends on the redox properties of the dyes; see ref 14 .

Computational Results. Method Benchmark. As the first step, we performed an extended benchmark study on MeADOTA to find the computational methodology representing the best compromise between speed of calculation and accuracy of the results to work with triangulenium dyes. The fastest method we tested is DFT/TD-DFT, for which we assessed three different functionals. The CC2 method was used as an intermediate method of proven fair accuracy but was not fast enough for extensive investigations in contrast to the DFT methods. Finally, the MS-RASPT2 method was used for some key calculations as it was extremely expensive in terms of time and computational resources, although with proven accuracy. The results of the benchmark study are reported in Table 3.

As can be seen from the data in Table 3, various methods gave quite different results. Thus, it is important to select the one that represents the best compromise.

First of all, it can be noticed that the data obtained with a fixed geometry (CC2/cc-pVQZ) and different methods/ functionals for the calculation of the excitation energies do not differ significantly from those obtained at geometries optimized with the corresponding methods. Therefore, we can assume that the photophysical properties of the tested molecule are not overly sensitive to the choice of method for geometry optimization. Hence, for the rest of the calculations, we used $\mathrm{B} 3 \mathrm{LYP} / \mathrm{cc}-\mathrm{pVTZ}$ as the functional of choice for efficient geometry optimizations.

Second, the values obtained from the CC2 calculations were $0.12-0.13$ for the D1 diagnostic, which is larger than the maximum acceptance of $\sim 0.04 / 0.05 .^{99}$ Thus, these calculations may not represent the optimal values to compare with but nonetheless have to be considered because they are also close to the MS-RASPT2 computed values. The few MS-RASPT2 values reported in Table 3 were obtained after a further internal benchmark on the method itself, regarding the number of virtual orbitals to be included (Table S12). The data in Table 3 were obtained with 371 virtual orbitals. Two different active spaces including two or three holes/excitations (PT2-2HE and PT2-3H, respectively) were also tested. The results show that 
Table 5. Calculated Transition Energies, Transition Dipole Moments, and Oscillator Strength for Light Absorption and Emission in ADOTA and DAOTA with Methyl and Phenyl Substituents ${ }^{a}$

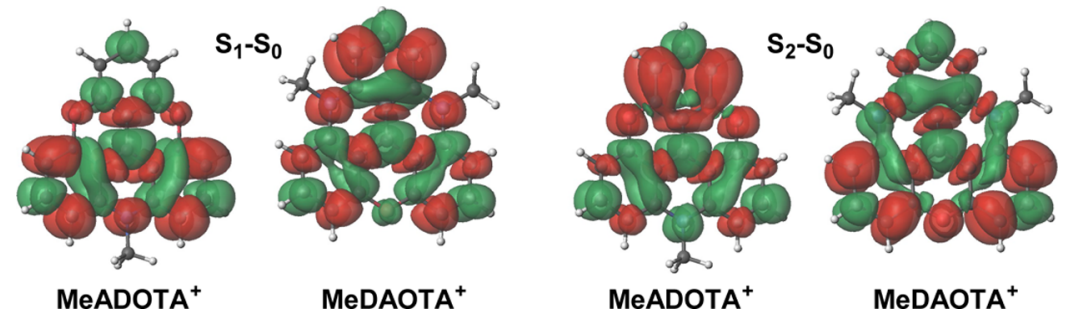

\begin{tabular}{|c|c|c|c|c|c|c|c|c|c|c|c|}
\hline & & \multicolumn{3}{|c|}{ calc. $S_{0} \rightarrow S_{1}$} & \multicolumn{3}{|c|}{ calc. $S_{1} \rightarrow S_{0}$} & \multicolumn{2}{|c|}{ Stokes' shift } & \multicolumn{2}{|c|}{$k_{\mathrm{f}} / n^{3}\left(10^{8} \mathrm{~s}^{-1}\right)^{b}$} \\
\hline & & $\Delta E\left(\mathrm{~cm}^{-1}\right)$ & $|\mu|(\mathrm{D})$ & $f$ & $\Delta E\left(\mathrm{~cm}^{-1}\right)$ & $|\mu|(\mathrm{D})$ & $f$ & calc. $\left(\mathrm{cm}^{-1}\right)$ & exp. $\left(\mathrm{cm}^{-1}\right)$ & calc. $\left(10^{8} \mathrm{~s}^{-1}\right)$ & exp. $\left(10^{8} \mathrm{~s}^{-1}\right)$ \\
\hline \multirow[t]{2}{*}{ ADOTA } & methyl- & 21400 & 3.70 & 0.138 & 19100 & 3.35 & 0.101 & 2300 & 270 & 0.25 & 0.12 \\
\hline & phenyl & 21100 & 4.07 & 0.164 & 18700 & 3.67 & 0.118 & 2400 & 360 & 0.28 & 0.13 \\
\hline \multirow[t]{2}{*}{ DAOTA } & dimethyl- & 21000 & 3.95 & 0.153 & 18600 & 3.47 & 0.106 & 2400 & 530 & 0.24 & 0.12 \\
\hline & diphenyl- & 20400 & 4.51 & 0.195 & 18200 & 3.95 & 0.133 & 2200 & 590 & 0.29 & 0.13 \\
\hline
\end{tabular}

${ }^{a}$ Corresponding computed Stokes' shifts and radiative rate constants are compared with the experimental values. The errors in the reported values are those inherent of the computational method used (energies: B3LYP/cc-pVQZ; moments: CAM-B3LYP/cc-pVQZ). Inset: the electron density difference plots for the first and second excited states of MeADOTA and MeDAOTA (green = positive; red $=$ negative). ${ }^{b} k_{\mathrm{f}}$ calculated following refs 94 and 101; the error is estimated to be less than $10 \%$.

the inclusion of three holes/excitations is not necessary for these kinds of molecules, as opposed to what was previously found. ${ }^{100}$

Considering both absorption and fluorescence data, we deemed the B3LYP functional with cc-pVQZ basis set to represent the best compromise in terms of speed for the computation of energy differences, whereas the CAM-B3LYP functional and the same basis set were chosen for the TDMs.

Absorption and Fluorescence Data. The calculated energies of the first excited states in the singlet and triplet manifold are shown in Table 4. It is worth to note the lowenergy splitting of the $S_{1}$ and $S_{2}$ states and $T_{1}$ and $T_{2}$ states. In $D_{3 h}$ symmetry, these states would collapse to degenerate states spanning the $x$ and $y$ axes, whereas in $C_{2 v}$, they fall into two different irreducible representations. ${ }^{12}$ In Table 4 , it can be noted that $T_{2}$ is just below $S_{1}$ for both ADOTA and DAOTA, suggesting viable intersystem axes. A cursory inspection of Table 4 shows that calculated energy differences are not in very good agreement with the experimental results. However, it is assumed that computed energy differences for ADOTA and DAOTA are more accurate, as they are in better agreement with the experimental data.

To examine the effect of the substituents on the nitrogen bridges, the absorption and emission processes were investigated; see Table 5. The experimental results did not show decisive differences between the six dyes, when considering the excited state kinetics (Table 1). The calculations show that the aryl-substituted dyes have a radiative rate constant $10 \%$ larger than the alkyl-substituted derivatives and that this is most pronounced for DAOTA. More notably, the method used overestimates the radiative rate constant by a factor of 2 . The substituent effect on the transition energy is most likely real but vanishes under the experimental conditions used. Similarly, the effect of substituents on the relative size of the transition energies is reproduced but overestimated by the calculations.

The Stokes' shift is vastly overestimated using the computational method. This suggests that the structural relaxation of the excited state is important in determining the observed emission energy and that it must occur in both dyes. In the experimental data, the Stokes' shift is significantly larger in DAOTA than that in ADOTA. As the dye system is charged, the solvation is dominated by the need to compensate for the charge. This is not affected by the electronic state of the dye, and thus the solvation is expected to be close to identical in the ground and the excited states. Therefore, assuming that differences in solvation are negligible between the two cationic dyes, the experimentally observed difference in Stokes' shift and the origin of the shift found by computations implies that the structural relaxation that occurs in the excited state of DAOTA is significantly larger than that occurs in ADOTA. The only difference between the two structures is the substitution of an oxa bridge with an aza bridge; thus, the increased relaxation must involve the structure around the nitrogen atoms such as a variation between pyramidal or planar as the dominating structure.

Closer inspection of Table 5 reveals that the transition probability given (e.g. as the oscillator strength) is reduced by $30 \%$ for light emission as compared with light absorption. By scrutinizing the data, it can be seen that this is due to the structural relaxation in $S_{1}$ : the relaxation reduces the FranckCondon overlap with the ground state, reducing the transition probability. The phenomenon is most likely overestimated by the model, which gives rise to an overestimation of both the reduction in oscillator strength and the Stokes' shift. As the reduced coupling between $S_{1}$ and $S_{0}$ still results in an overestimation of $k_{\mathrm{f}}$, and thus the transition probability, the computational results does not offer an explanation for the low rate constant observed for internal conversion in the azaoxatriangulenium dyes. The theoretical data do suggest increased structural relaxation as an explanation for the difference in the excited state kinetics between ADOTA and DAOTA. Electron density difference maps are included in Table 5; it has to be noted that all transitions occur with an increased electron density on the central carbon and that the plots confirm the experimentally assigned symmetries; see ref 12 .

Excited State Energy. The discussion so far has been focused on comparing the theory and experiment and understanding the excited state kinetics. The small differences in energy discussed here do not appear to influence the excited state kinetics; see Table 1. 

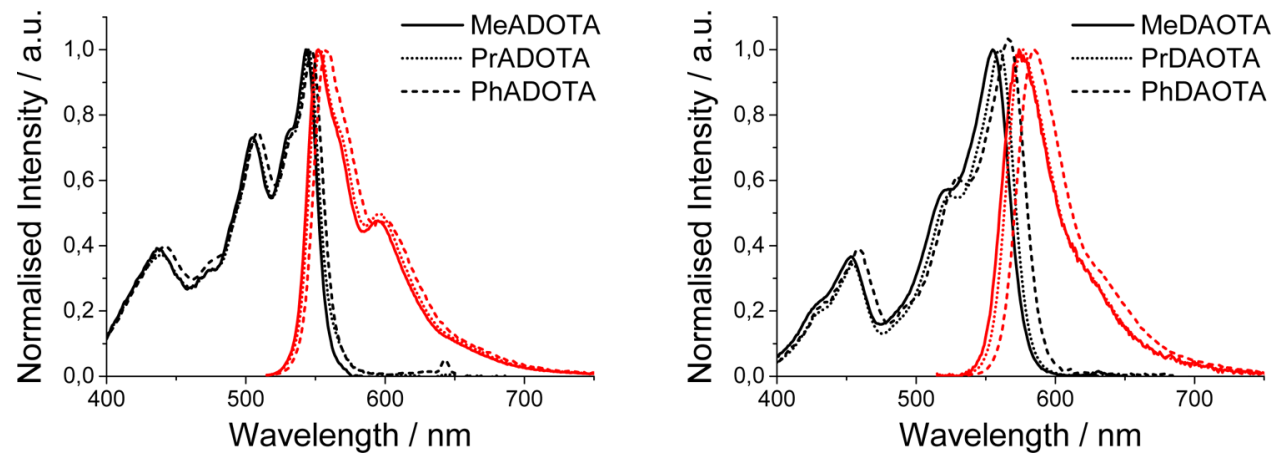

Figure 3. Comparison of substituent effects in the fluorescence excitation (black) and emission (red) spectra for the six investigated azaoxatriangulenium dyes in DCM.

Figure 3 shows the spectra of all six investigated dyes in the DCM solution. For ADOTA, the difference in the substituent on the single nitrogen bridge moves the energy of the first excited state up to $200 \mathrm{~cm}^{-1}$, whereas the same number for DAOTA is $330 \mathrm{~cm}^{-1}$ for two nitrogen substituents. In ADOTA, the effect is larger for the relaxed excited state compared with the Franck-Condon state; for DAOTA, there is no difference. The Stokes' shift increases for PhADOTA to 360 from 270 $\mathrm{cm}^{-1}$ in MeADOTA and PrADOTA. This indicates a more pronounced structural change in the $S_{1}$ state for the arylsubstituted ADOTA as compared with the alkyl-substituted derivatives.

The average Stokes' shift for DAOTA is $571 \mathrm{~cm}^{-1}$, which is significantly larger than that for ADOTA. In DAOTA, the Stokes' shift is not influenced by the substituent on the nitrogen bridges, although the overall larger Stokes' shift may dominate the substituent effect. The larger Stokes' shift observed for DAOTA may be linked to the faster rate of internal conversion found for this dye system, when retaining the assumption that the occurrence of structural reorganization is linked to the pathway of nonradiative deactivation.

Experimental and computational results agree on the energy difference when comparing the optical transitions in ADOTA and DAOTA and that the energy difference depends on the substituents on nitrogen. For absorption (the Franck-Condon state), the energy difference between ADOTA and DAOTA is 380,490 , and $600 \mathrm{~cm}^{-1}$ for methyl, propyl, and phenyl, whereas the difference in fluorescence (the relaxed $S_{1}$ state) is more pronounced with values at 690,750 , and $830 \mathrm{~cm}^{-1}$. Exclusively considering the energy gap law, the energy difference will give rise to a $10 \%$ larger rate constant for internal conversion in DAOTA compared with ADOTA, in the most extreme case. The observed difference in $k_{\mathrm{nr}}$ in DCM is $30 \%$ (Table 1 ), thus confirming that factors other than excited state energy must be determining the photophysical behavior observed for the azaoxa-triangulenium dyes.

Taken together, the computational results and the detailed energetic analysis bear out a small difference between ADOTA and DAOTA related to the relaxation of the excited state structure of the dyes. The small difference in structural relaxation, determined by the number of nitrogen donors in the fluorophore, may be the origin of the higher $k_{\mathrm{nr}}$ observed for DAOTA.

\section{CONCLUSIONS}

The photophysical properties of six azaoxa-triangulenium dyes were investigated in a series of steady-state and time-resolved spectroscopies. Corrected fluorescence quantum yields were reported for ADOTA and DAOTA. It was found that solvent effects smoothen the vibrational fine structure in the absorption and emission spectra and influence the rate of nonradiative deactivation of $S_{1}$, whereas the refractive index-corrected fluorescence rate constant was found to be independent of solvent. It was found that the substituents on the aza bridges influence the transition energy slightly but do not alter the rate of radiative or nonradiative deactivation of $S_{1}$. Molecular oxygen was found to influence the excited state kinetics of $S_{1}$, and we propose that, to an appreciable extent, nonradiative deactivation in the azaoxa-triangulenium dyes occurs via intersystem crossing to the triplet manifold and subsequent quenching of $\mathrm{T}_{1}$ by molecular oxygen. However, direct quenching of $S_{1}$ by molecular oxygen is also a possibility owing to the comparatively long singlet-state lifetime.

It was shown that B3LYP/cc-pVQZ energies and CAMB3LYP/cc-pVQZ TDMs on B3LYP/cc-pVTZ geometries can be used to calculate the excited state properties of triangulenium dyes but that this level of theory still struggles to describe delicate balances of forces involving space interaction. Although the experimental results did not find any optical transitions from the triplet manifold of ADOTA and DAOTA, the computational results show that these should be observable in the energy ranges investigated. We must conclude that the radiative processes in triplet manifold of these azaoxatriangulenium dyes have very low transition probabilities.

The results presented here allow the conclusion that the azaoxa-triangulenium dyes have a very low inherent rate of nonradiative deactivation from $S_{1}$, which in part is due to a low rate constant for quenching by molecular oxygen. Therefore, ADOTA and DAOTA are fluorophores with strong emission in the red, long fluorescence lifetimes, and high photostability that open new possibilities in the areas of fluorescence technology and bioimaging.

\section{ASSOCIATED CONTENT}

\section{S Supporting Information}

The Supporting Information is available free of charge on the ACS Publications website at DOI: 10.1021/acsomega.6b00211.

Absorption and emission spectra, linear fits used for fluorescence quantum yield determination, oxygen titrations, time-resolved emission decay profiles, calculated molecular coordinates and frequencies, computational details, and detector response curves (PDF) 


\section{AUTHOR INFORMATION}

\section{Corresponding Author}

*E-mail: TJS@chem.ku.dk (T.J.S.).

\section{ORCID ${ }^{\circ}$}

Peter R. Ogilby: 0000-0003-0165-5159

Stephan P. A. Sauer: 0000-0003-4812-0522

Thomas Just Sørensen: 0000-0003-1491-5116

\section{Notes}

The authors declare no competing financial interest.

\section{ACKNOWLEDGMENTS}

The authors would like to thank the Carlsberg Foundation, the Villum Foundation, the Danish Center for Scientific Computing, the Danish National Research Foundation, and the University of Copenhagen.

\section{REFERENCES}

(1) Laursen, B. W.; Krebs, F. C.; Nielsen, M. F.; Bechgaard, K.; Christensen, J. B.; Harrit, N. J. Am. Chem. Soc. 1998, 120, 12255.

(2) Laursen, B. W.; Krebs, F. C. Angew. Chem., Int. Ed. 2000, 39, 3432.

(3) Laursen, B. W.; Krebs, F. C. Chem.-Eur. J. 2001, 7, 1773.

(4) Bosson, J.; Gouin, J.; Lacour, J. Chem. Soc. Rev. 2014, 43, 2824.

(5) Stępień, M.; Gońka, E.; Żyła, M.; Sprutta, N. Chem. Rev. 2016,

DOI: 10.1021 /acs.chemrev.6b00076.

(6) Clar, E.; Stewart, D. G. J. Am. Chem. Soc. 1953, 75, 2667.

(7) Martin, J. C.; Smith, R. G. J. Am. Chem. Soc. 1964, 86, 2252.

(8) Laursen, B. W.; Sørensen, T. J. J. Org. Chem. 2009, 74, 3183.

(9) Sørensen, T. J.; Laursen, B. W. J. Org. Chem. 2010, 75, 6182.

(10) Westerlund, F.; Hildebrandt, C. B.; Sørensen, T. J.; Laursen, B. W. Chem.-Eur. J. 2010, 16, 2992.

(11) Adam, C.; Wallabregue, A.; Li, H.; Gouin, J.; Vanel, R.; Grass, S.; Bosson, J.; Bouffier, L.; Lacour, J.; Sojic, N. Chem.—Eur J. 2015, 21, 19243-19249.

(12) Thyrhaug, E.; Sørensen, T. J.; Gryczynski, I.; Gryczynski, Z.; Laursen, B. W. J. Phys. Chem. A 2013, 117, 2160.

(13) Dileesh, S.; Gopidas, K. R. Chem. Phys. Lett. 2000, 330, 397.

(14) Dileesh, S.; Gopidas, K. R. J. Photochem. Photobiol., A 2004, 162, 115.

(15) Nicolas, C.; Lacour, J. Org. Lett. 2006, 8, 4343.

(16) Nicolas, C.; Bernardinelli, G.; Lacour, J. J. Phys. Org. Chem. 2010, 23, 1049.

(17) Hammershøj, P.; Sørensen, T. J.; Han, B.-H.; Laursen, B. W. J. Org. Chem. 2012, 77, 5606

(18) Sørensen, T. J.; Hildebrandt, C. B.; Elm, J.; Andreasen, J. W.; Madsen, A. Ø.; Westerlund, F.; Laursen, B. W. J. Mater. Chem. 2012, 22, 4797.

(19) Wei, Z.; Wang, X.; Borges, A.; Santella, M.; Li, T.; Sørensen, J. K.; Vanin, M.; Hu, W.; Liu, Y.; Ulstrup, J.; Solomon, G. C.; Chi, Q.; Bjørnholm, T.; Nørgaard, K.; Laursen, B. W. Langmuir 2014, 30, 14868 .

(20) Baisch, B.; Raffa, D.; Jung, U.; Magnussen, O. M.; Nicolas, C.; Lacour, J.; Kubitschke, J.; Herges, R. J. Am. Chem. Soc. 2009, 131, 442. (21) Kubitschke, J.; Näther, C.; Herges, R. Eur. J. Org. Chem. 2010, 5041

(22) Krebs, F. C.; Laursen, B. W.; Johannsen, I.; Faldt, A.; Bechgaard, K.; Jacobsen, C. S.; Thorup, N.; Boubekeur, K. Acta Crystallogr., Sect. B: Struct. Sci. 1999, 55, 410.

(23) Maliwal, B. P.; Fudala, R.; Raut, S.; Kokate, R.; Sørensen, T. J.; Laursen, B. W.; Gryczynski, Z.; Gryczynski, I. PLoS One 2013, 8, No. e63043.

(24) Rich, R. M.; Mummert, M.; Gryczynski, Z.; Borejdo, J.; Gryczynski, I.; Sørensen, T. J.; Laursen, B. W.; Fudala, R. Single Molecule Spectroscopy and Superresolution Imaging VI. Proc. SPIE 2013, 859003.
(25) Rich, R. M.; Mummert, M.; Gryczynski, Z.; Borejdo, J.; Sørensen, T. J.; Laursen, B. W.; Foldes-Papp, Z.; Gryczynski, I.; Fudala, R. Anal. Bioanal. Chem. 2013, 405, 4887.

(26) Rich, R. M.; Stankowska, D. L.; Maliwal, B. P.; Sørensen, T. J.; Laursen, B. W.; Krishnamoorthy, R. R.; Gryczynski, Z.; Borejdo, J.; Gryczynski, I.; Fudala, R. Anal. Bioanal. Chem. 2013, 405, 2065.

(27) Sørensen, T. J.; Thyrhaug, E.; Szabelski, M.; Luchowski, R.; Gryczynski, I.; Gryczynski, Z.; Laursen, B. W. Methods Appl. Fluoresc. 2013, $1,025001$.

(28) Bora, I.; Bogh, S. A.; Santella, M.; Rosenberg, M.; Sørensen, T. J.; Laursen, B. W. Eur. J. Org. Chem. 2015, 6351-6358.

(29) Bogh, S. A.; Bora, I.; Rosenberg, M.; Thyrhaug, E.; Laursen, B. W.; Sørensen, T. J. Methods Appl. Fluoresc. 2015, 3, 045001.

(30) Bora, I.; Bogh, S. A.; Rosenberg, M.; Santella, M.; Sørensen, T. J.; Laursen, B. W. Org. Biomol. Chem. 2016, 14, 1091.

(31) Folmar, M.; Shtoyko, T.; Fudala, R.; Akopova, I.; Gryczynski, Z.; Raut, S.; Gryczynski, I. Chem. Phys. Lett. 2012, 531, 126.

(32) Raut, S. L.; Rich, R.; Shtoyko, T.; Bora, I.; Laursen, B. W.; Sørensen, T. J.; Borejdo, J.; Gryczynski, Z.; Gryczynski, I. Nanoscale 2015, 7, 17729.

(33) Sørensen, T. J.; Laursen, B. W.; Luchowski, R.; Shtoyko, T.; Akopova, I.; Gryczynski, Z.; Gryczynski, I. Chem. Phys. Lett. 2009, 476, 46.

(34) Shivalingam, A.; Vyšniauskas, A.; Albrecht, T.; White, A. J. P.; Kuimova, M. K.; Vilar, R. Chem.-Eur. J. 2016, 22, 4129.

(35) Wallabregue, A.; Moreau, D.; Sherin, P.; Lorente, P. M.; Jarolímová, Z.; Bakker, E.; Vauthey, E.; Gruenberg, J.; Lacour, J. J. Am. Chem. Soc. 2016, 138, 1752.

(36) Shivalingam, A.; Izquierdo, M. A.; Marois, A. L.; Vyšniauskas, A.; Suhling, K.; Kuimova, M. K.; Vilar, R. Nat. Commun. 2015, 6, 8178.

(37) Brouwer, A. M. Pure Appl. Chem. 2011, 83, 2213.

(38) Würth, C.; Grabolle, M.; Pauli, J.; Spieles, M.; Resch-Genger, U. Nat. Protoc. 2013, 8, 1535.

(39) Crosby, G. A.; Demas, J. N. J. Phys. Chem. 1971, 75, 991.

(40) Meech, S. R.; Phillips, D. J. Photochem. 1983, 23, 193.

(41) Scurlock, R. D.; Martire, D. O.; Ogilby, P. R.; Taylor, V. L.; Clough, R. L. Macromolecules 1994, 27, 4787.

(42) Arnbjerg, J.; Johnsen, M.; Frederiksen, P. K.; Braslavsky, S. E.; Ogilby, P. R. J. Phys. Chem. A 2006, 110, 7375.

(43) Salice, P.; Arnbjerg, J.; Pedersen, B. W.; Toftegaard, R.; Beverina, L.; Pagani, G. A.; Ogilby, P. R. J. Phys. Chem. A 2010, 114, 2518.

(44) Ogilby, P. R. Chem. Soc. Rev. 2010, 39, 3181.

(45) Bregnhøj, M.; Blázquez-Castro, A.; Westberg, M.; Breitenbach, T.; Ogilby, P. R. J. Phys. Chem. B 2015, 119, 5422.

(46) Wilkinson, F.; Helman, W. P.; Ross, A. B. J. Phys. Chem. Ref. Data 1995, 24, 663.

(47) Takizawa, S.-y.; Breitenbach, T.; Westberg, M.; Holmegaard, L.; Gollmer, A.; Jensen, R. L.; Murata, S.; Ogilby, P. R. Photochem. Photobiol. Sci. 2015, 14, 1831.

(48) Martí, C.; Jürgens, O.; Cuenca, O.; Casals, M.; Nonell, S. J. Photochem. Photobiol., A 1996, 97, 11.

(49) Westberg, M.; Holmegaard, L.; Pimenta, F. M.; Etzerodt, M.; Ogilby, P. R. J. Am. Chem. Soc. 2015, 137, 1632.

(50) Casida, M. E.; Huix-Rotllant, M. Ann. Rev. Phys. Chem. 2012, 63, 287.

(51) Dreuw, A.; Head-Gordon, M. Chem. Rev. 2005, 105, 4009.

(52) Runge, E.; Gross, E. K. U. Phys. Rev. Lett. 1984, 52, 997.

(53) Lee, C.; Yang, W.; Parr, R. G. Phys. Rev. B 1988, 37, 785.

(54) Yanai, T.; Tew, D. P.; Handy, N. C. Chem. Phys. Lett. 2004, 393, $51-56$.

(55) Zhao, Y.; Truhlar, D. G. Acc. Chem. Res. 2008, 41, 157-167.

(56) Silva-Junior, M. R.; Schreiber, M.; Sauer, S. P. A.; Thiel, W. J. Chem. Phys. 2008, 129, 104103.

(57) Charaf-Eddin, A.; Planchat, A.; Mennucci, B.; Adamo, C.; Jacquemin, D. J. Chem. Theory Comput. 2013, 9, 2749-2760.

(58) Laurent, A. D.; Jacquemin, D. Int. J. Quantum Chem. 2013, 113, 2019-2039.

(59) Adamo, C.; Jacquemin, D. Chem. Soc. Rev. 2013, 42, 845-856. 
(60) Charaf-Eddin, A.; Planchat, A.; Mennucci, B.; Adamo, C.; Jacquemin, D. J. Chem. Theory Comput. 2013, 9, 2749-2760.

(61) Laurent, A. D.; Jacquemin, D. Int. J. Quantum Chem. 2013, 113, 2019-2039.

(62) Adamo, C.; Jacquemin, D. Chem. Soc. Rev. 2013, 42, 845-856.

(63) Christiansen, O.; Koch, H.; Jørgensen, P. Chem. Phys. Lett. 1995, 243, 409-418.

(64) Schreiber, M.; Silva-Junior, M. R.; Sauer, S. P. A.; Thiel, W. J. Chem. Phys. 2008, 128, 134110.

(65) Sauer, S. P. A.; Schreiber, M.; Silva-Junior, M. R.; Thiel, W. J. Chem. Theory Comput. 2009, 5, 555-564.

(66) Silva-Junior, M. R.; Sauer, S. P. A.; Schreiber, M.; Thiel, W. Mol. Phys. 2010, 108, 453-465.

(67) Falden, H. H.; Falster-Hansen, K. R.; Bak, K. L.; Rettrup, S.; Sauer, S. P. A. J. Phys. Chem. A 2009, 113, 11995-12012.

(68) Dunning, T. H., Jr. J. Chem. Phys. 1989, 90, 1007.

(69) Dunning, T. H., Jr. J. Chem. Phys. 1989, 90, 1007.

(70) Roos, B. O.; Taylor, P. R.; Si=gbahn, P. E. M. Chem. Phys. 1980, $48,157$.

(71) Finley, J.; Malmqvist, P.-Å.; Roos, B. O.; Serrano-Andrés, L. Chem. Phys. Lett. 1998, 288, 299.

(72) Andersson, K.; Malmqvist, P.-Å.; Roos, B. O. J. Chem. Phys. 1992, 96, 1218.

(73) Malmqvist, P. Å.; Pierloot, K.; Shahi, A. R. M.; Cramer, C. J.; Gagliardi, L. J. Chem. Phys. 2008, 128, 204109.

(74) Roos, B. O.; Lindh, R.; Malmqvist, P.-Å.; Veryazov, V.; Widmark, P.-O. J. Chem. Phys. 2004, 108, 2851.

(75) Aquilante, F.; Malmqvist, P.-Å.; Pedersen, T. B.; Ghosh, A.; Roos, B. O. J. Chem. Theory Comput. 2008, 4, 694.

(76) Ghigo, G.; Roos, B. O.; Malmqvist, P.-Å. Chem. Phys. Lett. 2004, 396, 142.

(77) Forsberg, N.; Malmqvist, P.-Å Chem. Phys. Lett. 1997, 274, 196.

(78) Ahlrichs, R.; Bär, M.; Häser, M.; Horn, H.; Kölmel, C. Chem. Phys. Lett. 1989, 162, 165.

(79) Weigend, F.; Köhn, A.; Hättig, C. J. Chem. Phys. 2001, 116, 3175

(80) Frisch, M. J.; Trucks, G. W.; Schlegel, H. B.; Scuseria, G. E.; Robb, M. A.; Cheeseman, J. R.; Scalmani, G.; Barone, V.; Mennucci, B.; Petersson, G. A.; Nakatsuji, H.; Caricato, M.; Li, X.; Hratchian, H. P.; Izmaylov, A. F.; Bloino, J.; Zheng, G.; Sonnenberg, J. L.; Hada, M.; Ehara, M.; Toyota, K.; Fukuda, R.; Hasegawa, J.; Ishida, M.; Nakajima, T.; Honda, Y.; Kitao, O.; Nakai, H.; Vreven, T.; Montgomery, J. A., Jr.; Peralta, J. E.; Ogliaro, F.; Bearpark, M.; Heyd, J. J.; Brothers, E.; Kudin, K. N.; Staroverov, V. N.; Kobayashi, R.; Normand, J.; Raghavachari, K.; Rendell, A.; Burant, J. C.; Iyengar, S. S.; Tomasi, J.; Cossi, M.; Rega, N.; Millam, J. M.; Klene, M.; Knox, J. E.; Cross, J. B.; Bakken, V.; Adamo, C.; Jaramillo, J.; Gomperts, R.; Stratmann, R. E.; Yazyev, O.; Austin, A. J.; Cammi, R.; Pomelli, C.; Ochterski, J. W.; Martin, R. L.; Morokuma, K.; Zakrzewski, V. G.; Voth, G. A.; Salvador, P.; Dannenberg, J. J.; Dapprich, S.; Daniels, A. D.; Farkas, Ö.; Foresman, J. B.; Ortiz, J. V.; Cioslowski, J.; Fox, D. J. Gaussian 09, Revision B.01; Gaussian Inc.: Wallingford CT, 2010.

(81) Frisch, M. J.; Trucks, G. W.; Schlegel, H. B.; Scuseria, G. E.; Robb, M. A.; Cheeseman, J. R.; Scalmani, G.; Barone, V.; Mennucci, B.; Petersson, G. A.; Nakatsuji, H.; Caricato, M.; Li, X.; Hratchian, H. P.; Izmaylov, A. F.; Bloino, J.; Zheng, G.; Sonnenberg, J. L.; Hada, M.; Ehara, M.; Toyota, K.; Fukuda, R.; Hasegawa, J.; Ishida, M.; Nakajima, T.; Honda, Y.; Kitao, O.; Nakai, H.; Vreven, T.; Montgomery, J. A., Jr.; Peralta, J. E.; Ogliaro, F.; Bearpark, M.; Heyd, J. J.; Brothers, E.; Kudin, K. N.; Staroverov, V. N.; Kobayashi, R.; Normand, J.; Raghavachari, K.; Rendell, A.; Burant, J. C.; Iyengar, S. S.; Tomasi, J.; Cossi, M.; Rega, N.; Millam, J. M.; Klene, M.; Knox, J. E.; Cross, J. B.; Bakken, V.; Adamo, C.; Jaramillo, J.; Gomperts, R.; Stratmann, R. E.; Yazyev, O.; Austin, A. J.; Cammi, R.; Pomelli, C.; Ochterski, J. W.; Martin, R. L.; Morokuma, K.; Zakrzewski, V. G.; Voth, G. A.; Salvador, P.; Dannenberg, J. J.; Dapprich, S.; Daniels, A. D.; Farkas, Ö.; Foresman, J. B.; Ortiz, J. V.; Cioslowski, J.; Fox, D. J. Gaussian 09, Revision B.01; Gaussian Inc.: Wallingford CT, 2010.
(82) Aquilante, F.; De Vico, L.; Ferré, N.; Ghigo, G.; Malmqvist, P. Å.; Neogrády, P.; Pedersen, T. B.; Pitoňák, M.; Reiher, M.; Roos, B. O.; Serrano-Andrés, L.; Urban, M.; Veryazov, V.; Lindh, R. J. Comput. Chem. 2010, 31, 224.

(83) Kikuchi, K.; Sato, C.; Watabe, M.; Ikeda, H.; Takahashi, Y.; Miyashi, T. J. Am. Chem. Soc. 1993, 115, 5180.

(84) Cabrerizo, F. M.; Arnbjerg, J.; Denofrio, M. P.; Erra-Balsells, R.; Ogilby, P. R. ChemPhysChem 2010, 11, 796.

(85) Kristiansen, M.; Scurlock, R. D.; Iu, K. K.; Ogilby, P. R. J. Phys. Chem. 1991, 95, 5190.

(86) Montalti, M.; Credi, A.; Prodi, L.; Gandolfi, M. T. Handbook of Photochemistry, 3rd ed.; CRC Press: Boca Raton, 2006.

(87) Dewar, M. J. S. J. Chem. Soc. 1950, 2329-2334.

(88) Griffiths, J. Colour and Constitution of Organic Molecules; Academic Press: London, 1976.

(89) Valeur, B. Molecular Fluorescence: Principles and Applications; Wiley-VCH: Weinheim, 2002.

(90) Turro, N. J. Modern Molecular Photochemistry; University Science Books: Sausalito, 1991.

(91) Laursen, B. W.; Reynisson, J.; Mikkelsen, K. V.; Bechgaard, K.; Harrit, N. Photochem. Photobiol. Sci. 2005, 4, 568.

(92) Westerlund, F.; Elm, J.; Lykkebo, J.; Carlsson, N.; Thyrhaug, E.; Åkerman, B.; Sørensen, T. J.; Mikkelsen, K. V.; Laursen, B. W. Photochem. Photobiol. Sci. 2011, 10, 1963.

(93) Hirayama, S.; Phillips, D. J. Photochem. 1980, 12, 139.

(94) Lewis, J. E.; Maroncelli, M. Chem. Phys. Lett. 1998, 282, 197.

(95) Lewis, G. N.; Calvin, M. Chem. Rev. 1939, 25, 273.

(96) Reynisson, J.; Wilbrandt, R.; Brinck, V.; Laursen, B. W.; Nørgaard, K.; Harrit, N.; Brouwer, A. M. Photochem. Photobiol. Sci. 2002, 1, 763.

(97) Ware, W. R. J. Phys. Chem. 1962, 66, 455.

(98) Kasha, M. Acta Phys. Pol., A 1999, 95, 15-36.

(99) Janssen, C. L.; Nielsen, I. M. B. Chem. Phys. Lett. 1998, 290, 423.

(100) Anda, A.; Hansen, T.; De Vico, L. J. Chem. Theory Comput. 2016, 12, 1305 .

(101) Birks, J. B. Photophysics of Aromatic Molecules; WileyInterscience: London, 1970. 